\title{
HIPÓCRATES NÃO INVENTOU NADA: TERAPIAS POPULARES EM INSCRIÇÕES DE CURA ${ }^{1}$
}

Clarisse Pretre ${ }^{2}$

\section{Resumo}

Há muito tempo tem se pensado que a medicina hipocrática na antiguidade era oposta à medicina divina: Uma era racional, a outra era uma mistura de superstição e religião. Este artigo pretende demonstrar por meio de alguns exemplos das fontes textuais da Grécia antiga, que ambas as medicinas, uma dos deuses e a outra dos homens, exploraram os mesmos fundos empíricos das técnicas tradicionais de tratamento. Pretendemos agora matizar esta divisão demasiadamente esquemática entre as duas medicinas.

\section{Palavras-Chave}

Ascelpio; antiguidade grega; medicina popular; medicina divina; epigrafia.

\begin{abstract}
. Abstract
It has long been thought that the Hippocratic medicine in the Antiquity was opposed to the divine medicine: one was rational, the other was a mixture of superstition and religion. This article attempts to show by some examples from ancient Greek text sources that both medicines, one of the gods and one of the men, have exploited the same empirical funds from traditional care techniques. So we must now nuance the too schematic division between the two medicines.
\end{abstract}

\section{Keywords}

Asclepius; Greek antiquity; popular medecine; divine medecine; epigraphy.

\footnotetext{
${ }^{1}$ Texto traduzido por Jonathan Cruz Moreira. Mestando em História Universidade Federal de São

Paulo. email: jonathan.cruzmoreira@gmail.com

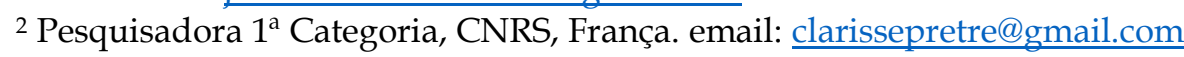


Quando alguém procura nas fontes textuais gregas por uma evidência da expressão "medicina popular", fica claro que isto não existe. Esta noção resulta, na verdade, de uma construção moderna que tem origem em uma definição negativa: Medicina popular não é nem " medicina " profissional" , nem a medicina praticada pelos deuses.

A divisão frequentemente levantada entre os tipos de medicina, na medida em que existem, coloca, portanto, as práticas de um médico treinado em uma "escola" de Cós, Alexandria ou Cnido, por exemplo, em oposição a práticas que não fazem parte de uma educação formal, como observações empíricas, e que muitas vezes são envolvidas com práticas religiosas e supersticiosas ou, de fato, ações mágicas.

A oposição é, ainda assim, artificial, já que sabemos que escolas institucionalizadas não existiram realmente. Ao Invés disso, métodos e modos de pensamento eram transmitidos individualmente de um mestre para um estudante, no quadro de um contexto familiar, como exposto claramente no juramento hipocrático: "Transmitirei os preceitos, as lições orais e todo o resto do ensinamento aos meus filhos, aos do meu mestre e aos alunos vinculados por acordo e juramento de acordo com a lei médica, mas a nenhuma outra pessoa". Além disso, mesmo que a medicina profissional seja a campeã do racionalismo, refutando o conceito da causalidade divina das doenças, os estudantes de Hipócrates apresentavam a si mesmos como descendentes de Esculápio e, da mesma forma, a ligação entre religião e medicina continua.

É difícil, portanto, caracterizar cada um destes três tipos de medicina segundo seus métodos, pois há muito em comum em termos de suas terapias, patologias, e na ligação permanente que se forma entre homens e deuses quando ocorre uma doença.

Isso vale para o período Homérico, quando a medicina estava apenas em sua infância: Então, cirurgia significava sangria, a extração de flechas, ou amputação, e tratamentos consistiam em cataplasmas, ou no consumo de sucos vegetais destinados a acalmar a dor. Os deuses eram frequentemente os inventores dos remédios usados pelos homens ${ }^{3}$, ainda que certos homens já fossem reconhecidos por suas habilidades em tratamentos e curas. No livro IX da Ilíada, o médico Machaon está ferido e recebe atenção especial: " por que um único medico vale muitos homens, por extrair flechas por incisão, e por aplicar remédios calmantes nos ferimentos". ${ }^{4}$

\footnotetext{
${ }^{3}$ Os nomes das plantas também foram, muitas vezes, inspirados pelos deuses. Cf. Fabre A-J Mythologie et plantes médicinales de l'Antiquité Hist Sci Med 2003;37-1:65-87.

${ }^{4}$ Iliada XI, 513-515.
} 
No início do período clássico, a medicina foi formalizada e dividida em dietética, farmacêutica e cirurgia, mas a intervenção dos deuses permanecia inquestionada. Isso é provado em Prometeu Acorrentado, de Ésquilo, no qual o Titã relembra seu papel primordial na criação da medicina. " Por falta de medicamentos, todos os homens estariam morrendo; mas fui eu quem os ensinou a compor remédios salutares. " 5

Pode-se pensar que a ascensão da medicina hipocrática sinalizaria o fim destas práticas terapêuticas populares inspiradas pelos deuses. Certas fontes epigráficas do século IV atestam, no entanto, a força da medicina empírica; os primeiros iamata, textos escritos principalmente no santuário de Esculápio em Epidauro ${ }^{6}$, são contemporâneos de Hipócrates e, portanto, do início do confronto entre a crença na casualidade divina e racionalismo médico. Mesmo que os iamata tenham sido concebidos para a glória do deus de cura, eles também ofereciam uma mistura de imprecisão lexical esperada, uma vez que sacerdotes e não médicos oficiaram no santuário - e procedimentos médicos racionais derivados de terapias tradicionais. A medicina descrita nos iamata é uma continuação da medicina popular, combinando princípios minerais e orgânicos que eram conhecidos já há muito tempo.

Aqui não é o lugar para enumerar todos as formas de terapia "popular" praticadas nos santuários dos deuses de cura. Em vez disso, focaremos em alguns exemplos que ressaltam uma espécie de recorrência tipológica de remédios e gestos originados em técnicas tradicionais, mas que mais tarde inspiraram a medicina profissional.

Deste modo, preparados tópicos eram algumas vezes compostos de ingredientes que dificilmente possuíam individualmente qualquer valor terapêutico, mas que, uma vez misturados, se tornavam ativos.

O cataplasma prescrito por Esculápio para P. Granio Rufo é um testemunho desta eficiência:

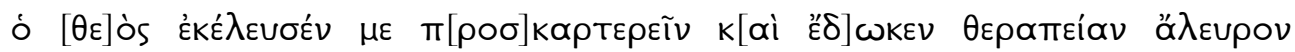

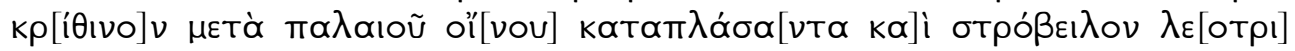

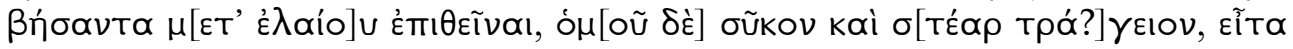

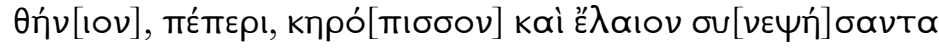

After having made a poultice of wheat flour and old wine, and after having reduced into a fine powder pine nuts with oil, apply them, at the same time as some

\footnotetext{
5 Prometeu Acorrentado, 478-483.

${ }^{6}$ Mas também Labena em Creta e, depois, Roma
} 
fig and some goat fat, then milk, pepper, and after having mixed, some ointment of wax and pitch with some oil.7

O uso destes elementos ( farinha de trigo, vinho velho, pinhões, óleo, figo, gordura de cabra, leite, pimenta, cera, alcatrão) pode ser observado em outros remédios tradicionais, mas é interessante notar que sua verdadeira garantia médica vem um século e meio depois com Celso, que usou estes ingredientes em suas receitas para suavizar cataplasmas e extrações em casos de escrófula. ${ }^{8}$

Da mesma forma, uma mulher agradeceu a Esculápio por ter curado uma ulceração em seu dedo:

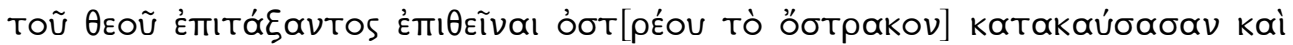

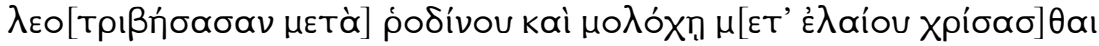

The god prescribed that she should apply an oyster shell after having completely burned and reduced it into a fine powder with some rose, and to rub it with mallow oil. ${ }^{9}$

$\mathrm{O}$ uso de alguns destes ingredientes para ulcerações era raro na medicina "profissional", aparecendo apenas em alguns medicamentos Hipocráticos contendo cinzas de ostra. Isso foi muitas vezes incorporado em alimentos em certas dietas recomendadas, mas raramente tinha um valor terapêutico real. É necessário aguardar por autores posteriores para ver a síntese das qualidades deste pó. Galeno utilizava a seu modo, para um caso de inflamação da glândula parótida: " Cinzas de conchas de ostras têm a mesma qualidade quando aplicadas com mel"10, mas nunca eram usadas para a composição de unguentos e bálsamos para uso externo.

A ulceração no dedo da mulher não se beneficiou de nenhuma intervenção cirúrgica, nem de qualquer incisão, mas de uma aplicação de óleo de malva: este também é um traço de uma terapia popular, em que as aplicações de plantas foram privilegiadas mais do que operações invasivas. Malva foi, de fato, usada na antiga farmacopeia por seu valor no tratamento de várias picadas e Plínio, o Velho, bem depois das inscrições de Lebena, descreveu suas propriedades:

This plant has efficacious properties against all stings, especially those of scorpions, wasps and similar insects, and against the bite of the shrew. Moreover, those who

\footnotetext{
${ }^{7}$ Inscriptiones Creticae I XVII 18

8 Celso De medicina Nis5 16-17

${ }^{9}$ Inscriptiones Creticae I XVII 19

${ }^{10}$ Galeno De compositione medicamentorum secundum locos liber III, cap. II, K12, 669 1. 5.
} 
have previously rubbed themselves with any of the mallows pounded in oil, or have some on them, will not be bitten ${ }^{11}$

Mais uma vez, a mistura de ingredientes para os mais variados tratamentos existia antes da medicina profissional. Fora das aplicações tópicas, as decocções e poções tradicionalmente usadas incluíam elementos com qualidades que às vezes não eram aceitas pelos médicos. É também sintomático que o termo $\chi 0 \lambda o ̀ s$, que de Platão a Teofrasto sempre designou suco de fruta e seiva, assumiu o novo sentido de "decocção" pela primeira vez nos iamata, um vetor evidente de medicina popular e empírica. $\mathrm{Na}$ literatura médica, Dioscórides usou seu significado original quando falou

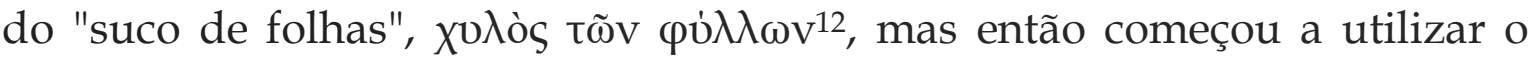
termo para todos os tipos de misturas, às vezes, quando o mel era incluso na composição ${ }^{13}$.

De acordo com Galeno, $\chi 0 \lambda$ ós era mais frequentemente o resultado de uma

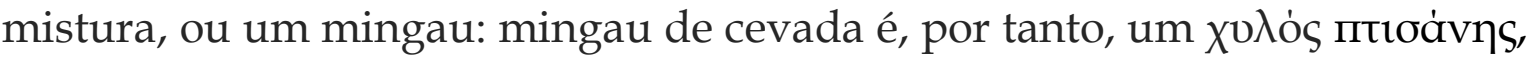
e certas misturas que eram diluídas em água ${ }^{14}$.

Os iamata incluem numerosos exemplos de poções complexas das quais não encontramos traços nos tratamentos hipocráticos.

Este é o caso de P. Granio Rufo, atacado por uma tosse purulenta severa, que se beneficiou de uma mistura composta de inúmeros ingredientes: suas propriedades terapêuticas foram comprovadas quando usadas separadamente, mas a fabricação de um remédio feito combinando todos eles é atestada pela primeira vez nos iamata e testemunha a engenhosidade da medicina popular em comparação com terapias na medicina hipocrática.

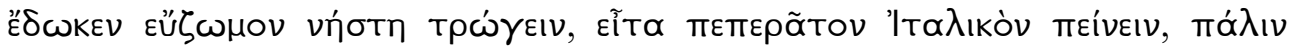

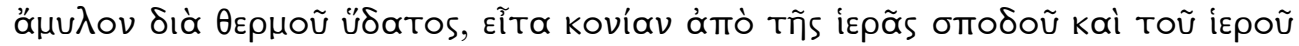

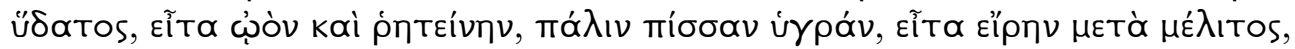

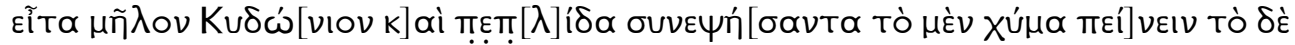

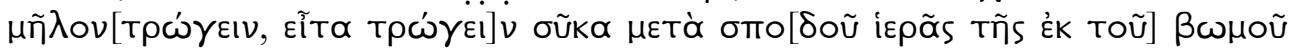

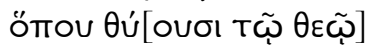

He had me eat arugula on an empty stomach, then drink peppered Italian wine, then starch in hot water, powder of sacred ash in holy water, an egg with pine resin, and also raw pitch, then iris in honey; then he had me drink quince juice mixed with spurge, eat an apple, then a fig with sacred ash coming from the altar on which one sacrifices to the god. ${ }^{15}$

\footnotetext{
11 Plínio, o velho Historia Naturalis 20, 84

12 Dioscorides De materia medica I 80, 1, 1. 1 (Wellmann)

${ }^{13}$ Dioscorides De materia medica I 126, 1, 1. 3;II, 151, 1, 7 (Wellmann)

${ }^{14}$ Galeno De sanitate tuenda liber IV, cap. IV, K6, p. 260, 1. 15. SESE. 5. Galien, De alimentarum facultatibus,

liber I, cap. VI, K6, p. 497, 1.4

${ }^{15}$ Inscriptiones Creticae I XVII, 17
} 
O valor terapêutico dos diferentes princípios ativos usados durante o tratamento deste paciente baseia-se muito em sua associação. Se considerarmos os ingredientes em detalhes, rúcula usada isoladamente possuía propriedades que eram essencialmente diuréticas e afrodisíacas; amido era usado na cura de problemas digestivos e intestinais gerais; marmelo era acima de tudo conhecido pela sua propriedade em acalmar os intestinos, mentrasto era um purgante renomado, e o figo era até mesmo considerado perigoso pois poderia causar distúrbios de humor. A presença de pó de cinzas sagradas acompanhadas de água sagrada dá a entender o caráter divino da terapia e não possui princípios ativos terapêuticos. Isso é remanescente de um iama posterior, do segundo século de nossa era, no qual uma pleurisia era curada quando o deus fazia um oráculo: "Permita que ele tome algumas das cinzas no altar triangular, permita que ele misture isto com vinho e aplique em seu lado. ${ }^{16}$ " A eficácia das cinzas no cataplasma quente poderia ser aceita no segundo caso, mas no primeiro, seu papel na composição do remédio é estritamente simbólico e atesta a força das crenças populares que infiltraram práticas terapêuticas com aparências racionais.

P. Granio Rufo foi posteriormente curado de sua doença pulmonar pela interação de uma mistura de ingredientes que não possuíam propriedades anti tosse quando tomadas individualmente. Novamente, medicina empírica provou a si mesma ao ponto no qual Celsius ${ }^{17}$ havia se inspirado um século antes na sessão que dedicou à tosse, sintetizando algumas de suas medicações. Mesmo os figos eram cozidos nas panelas, não de outro modo, prescreveu a Granio Rufo nas panelas sagradas do santuário de Esculápio. Também presentes estavam amido e água sagrada. Isso serve como um bom exemplo da assimilação das terapias populares pela medicina profissional.

Além dos remédios para uso externo ou interno sobre cujas propriedades curativas não há dúvida, certas formas de terapias parecem ter vindo de uma tradição médica popular que não foi retomada mais tarde como parte de práticas racionais. A intervenção de elementos exteriores não relacionados à farmacopeia ou cirurgia atestam não só a força da medicina popular, mas também a uma certa forma de conservadorismo contra a qual a medicina hipocrática continuou a lutar e denunciar.

A presença nos iamata de animais que ajudaram a curar pacientes é sem dúvida o processo terapêutico mais firmemente ancorado na tradição mais antiga de terapia. A relação entre o homem e o animal na Antiguidade

\footnotetext{
16 Inscriptiones Graecae XIV 966

17 Celso De medicina Nis4:4, 4
} 
evoluiu ao longo dos séculos. Enquanto os épicos homéricos estabeleceram uma relação quase igualitária entre os dois, opondo seu estado de mortalidade ao dos deuses imortais, o advento do logos no período arcaico colocou os animais em uma posição inferior definida perfeitamente por Isócrates. ${ }^{18}$ Nos iamata, o envolvimento ativo de certos animais rompe com esse esquema racional, incluindo-os diretamente no processo terapêutico resultante das crenças populares.

Assim, o cão é um dos animais mais recorrentes em atos de cura, embora os gregos muitas vezes o tenham considerado um animal impuro. Nas inscrições de Epidauro, dois filhos foram curados de uma úlcera e cegueira pelos cães do santuário:

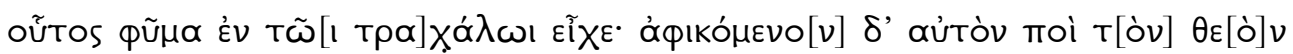

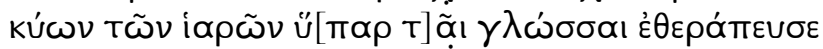

One had an abscess in his neck. When he came to the god, a sanctuary dog bathed him while awake with his tongue and he was returned to health. ${ }^{19}$

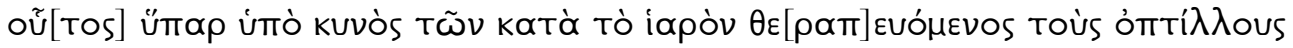
ن́y[ı̀े]s ámĩ $\lambda \theta \varepsilon$

One returned to good health because his eyes were washed by one of the dogs of the sanctuary while he was awake. ${ }^{20}$

Pausânias relata que um dos cães havia sido representado aos pés da estátua de Esculápio em Epidauro, pelo escultor Trasimedes de Paros ${ }^{21}$. Ele também relata a lenda segundo a qual o bebê Esculápio, abandonado ao cuidado de uma cabra por sua mãe Coronis, tinha sido guardado por um cão pastor ${ }^{22}$. Isso explica a consideração concedida aos cães nos santuários do deus, da mesma forma que as serpentes, embora a medicina hipocrática os considerasse animais impuros. No entanto, se o uso de saliva de cão para curar feridas pode parecer desprovido de toda validade racional, na prática demonstra mais uma vez o grande conhecimento empírico demonstrado pelos curandeiros dos templos: diagnósticos retrospectivos comprovam a eficiência desta terapia de contato, sendo a saliva canina caracterizada por uma concentração de leucócitos que estão associados a ingredientes ativos de limpeza presentes em sua constituição, muito mais elevados do que na saliva humana ${ }^{23}$

\footnotetext{
${ }^{18}$ Isocrates Nicocles of the Cyprians:3, 5-6.

${ }^{19}$ Inscriptiones Graecae IV2 1, 122, XXVI

${ }^{20}$ Inscriptiones Graecae IV2 1, 121, XX.

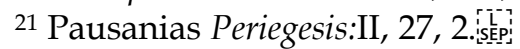

22 Pausanias Periegesis:II, 26, 4.d

${ }^{23}$ Duncan AW, Maggi RG, Breitschwerdt EB Bartonella DNA in dog saliva Emerg Infect Dis 2007;13:1948-1950
} 
Esta técnica de tratamento com saliva de cão que claramente se desenvolveu a partir de uma tradição popular; foi restaurada mais tarde nos escritos animais de Eliano. Só então o cão recuperou a função que tinha sido dele com Esculápio: o animal sabia escolher as ervas curativas, sua saliva tinha propriedades antissépticas e, finalmente, ele sentia doenças e, portanto, impedia que se desenvolvessem a estágios incuráveis ${ }^{24}$

O outro animal associado à cura é a serpente, que combina o simbolismo e a crença religiosa esculapiana com a sua eficácia terapêutica: às vezes é difícil distinguir entre ação médica real e superstição religiosa ligada ao imaginário popular da serpente e de Esculápio. Os mitos da fundação dos santuários reservam certamente um lugar central para a serpente: assim a cidade de Halieis explica a construção de seus temenos com a chegada de uma serpente que escolta um inválido que não tinha sido curado em Epidauro ${ }^{25}$. A história é comparável à lenda da fundação do Asclepeion na ilha do Tibre em Roma, quando, atingido por uma epidemia em 293 a.C, enviou uma embaixada para encontrar o deus em Epidauro, a fim de fundar um templo: a sua epifania divina ocorreu sob a forma de uma serpente que escolheu o local de seu futuro culto em Roma. ${ }^{26}$

No entanto, Aristófanes, contemporâneo de certos iamata epidaurianos, já não hesitou em seu Pluto de zombar da crença popular no poder curativo da serpente. O protagonista, acompanhando o seu mestre durante sua incubação no santuário, está mais preocupado com a comida deixada em oferenda ao deus do que com a cura; para conseguir um prato de mingau, ele falsifica a intervenção de uma serpente: "A velha, ouvindo o barulho que eu estava fazendo, estende a mão: eu assobio, eu a agarro, e eu a mordo, como se eu fosse uma serpente sagrada. Ela puxa a mão de volta imediatamente $^{27}$... "Além disso, é o próprio Pluto que é curado de sua cegueira por duas serpentes. "Estas, tendo discretamente deslizado sob o manto, lambeu suas pálpebras, como me pareceu ... Pluto levantou vendo claramente."

Um relevo de Epidauro carrega o mesmo tipo de cena com um homem idoso com os pés inchados carregado em uma maca debaixo de uma árvore; seus escravos trouxeram a serpente que o curará. ${ }^{28}$

\footnotetext{
${ }^{24}$ Eliano History of Animals V, 46 and VI, 16

${ }^{25}$ IG IV $^{2} 1,122$, XXXIII

${ }^{26}$ Ovídio Metamorphoses:XV, 622-744

${ }^{27}$ Aristófanes Pluto ( A Riqueza), :689-690 e 735-736

${ }^{28}$ Hamperl H Versuch der Deutung einer Wunderheilung von Epidauros, Archäologischer Anzeiger

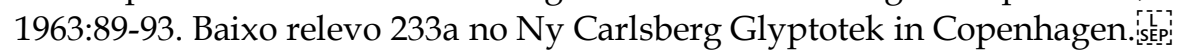


A intervenção curativa das serpentes é, portanto, de dois tipos nos textos epidaurianos: pela mordida e aplicação da saliva de um lado, e pelo simples contato do outro, provendo mais um poder divino do que um verdadeiro tratamento.

Como com o cão, reconhece-se na saliva de serpentes poderes antissépticos que não foram reconhecidos por profissionais médicos antigos, apesar da validade científica desta crença ${ }^{29}$. Assim, um homem atacado por uma ulceração se beneficiou deste tipo de tratamento:

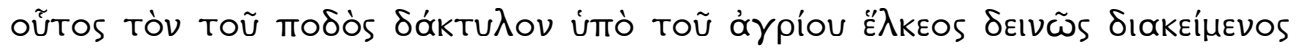

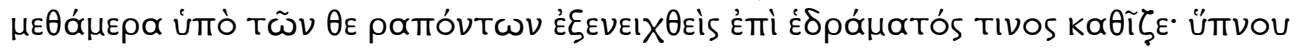

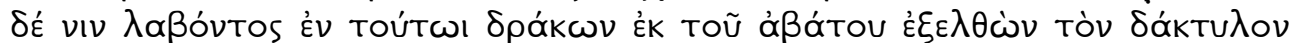

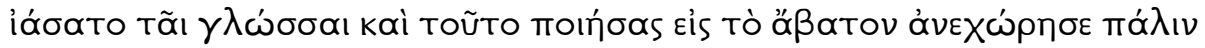

This one's toe was in a bad state because of a nasty swelling. That day, he had been carried by servants and remained seated on a chair. As he was taken by sleep, a serpent coming out of the abaton cured his foot with his tongue, and after this, returned again into the abaton. 30

Em outra, o abcesso de uma mulher foi incisado pelas presas de uma víbora:

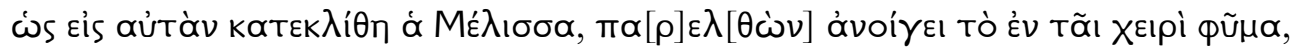

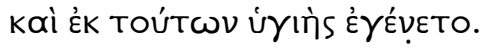

When Melissa lay down, the viper arrived by her side and opened the abscess on her hand, and following this, Melissa recovered her health. ${ }^{31}$

Este caso de incisão por picada é um dos raros atestados de uma prática cirúrgica transposta para um procedimento popular, com a serpente substituindo a mão do cirurgião na abertura e esvaziamento da ferida.

Os outros casos da intervenção de uma serpente nos iamata relacionam-se possivelmente mais a uma fantasia sexual do que a uma atividade terapêutica verdadeira. Nas duas histórias, as mulheres vêm a Epidauro para abordar sua esterilidade:

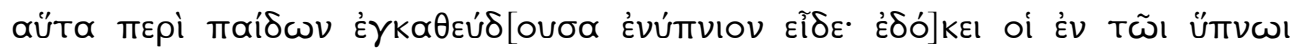

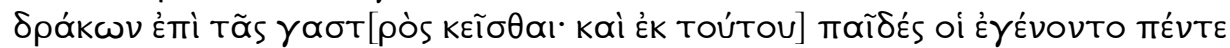

When she came to sleep here in order to have children, she had a vision in a dream. She believed in her sleep that a serpent coiled up on her belly. After this, she had five children.

\footnotetext{
${ }^{29}$ Angeletti LR, Agrimi U, Curia C, French D, Mariani-Costantini R Healing rituals and sacred serpents. Lancet 1992;340:223-225

${ }^{30}$ Inscriptiones Graecae IV 2 1, 121, XVIII

${ }^{31}$ Inscriptiones Graecae IV ${ }^{2}$ 1, 123, XLV
} 


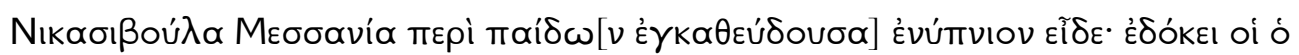

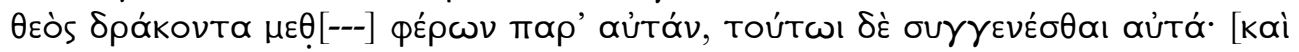

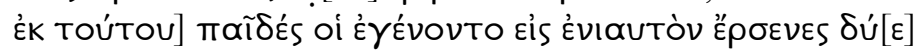

Nikasiboula of Messene, who came to sleep here on the subject of children, had a vision in a dream: she believed that the god had carried a serpent close to her and that she became one with it. Following this, she had two boys within the year. ${ }^{32}$

Além do simbolismo fálico da história, retomado mais tarde por Artemidoro $^{33}$, devemos acrescentar o prestígio da hierogamia, mesmo na forma animal. A crença permaneceu popular aqui, mas derivou da mudança de ações terapêuticas para as religiosas.

Estes exemplos, entre outros, também demonstram que a presença de atendentes auxiliando nas intervenções terapêuticas nos santuários de cura está assegurada. Os iamata são o reflexo inverso das teorias médicas racionais: a força da crença popular na ação divina foi necessariamente infiltrada pelos métodos hipocráticos, principalmente pelas técnicas cirúrgicas, mas também pelo conhecimento ancestral do uso das plantas para os mais variados remédios.

As terapias descritas nestas inscrições não podem de modo algum ser assimiladas às dos charlatães, e as práticas mágico-religiosas como encantamentos estão ausentes dos casos acima.

As motivações que trouxeram um inválido para recorrer a essas terapias divinas ao invés de medicina profissional ainda não foram compreendidas. Muitas vezes, é um retorno às práticas conhecidas por um longo tempo, seguindo um empreendimento em medicina hipocrática. Uma visita ao santuário de Esculápio muitas vezes constituiu uma última esperança de cura, devido à aliança reconfortante da medicina empírica e da religião. Assim Aristágoras de Trezene, depois de numerosos contratempos com médicos, virou-se para Esculápio que a curou de uma tênia ${ }^{34}$. A medicina hipocrática ainda estava em sua infância e os textos epigráficos relacionam os sucessos do deus através de métodos e terapêutica próximos aos da medicina popular.

Longe de desaparecer na esteira dos avanços médicos racionais, a medicina popular encontrou na terapia divina um meio de assegurar sua continuidade. Os iamata constituem uma forma escrita indispensável à tradução do conhecimento ancestral.

\footnotetext{
32 Inscriptiones Graecae IV2 1, 122, XXXIX et XLII

33 Oneirocritica 2,13 and 4,66

${ }^{34}$ Inscriptiones Graecae IV2 1, 122, XXIII
} 